\title{
LCP hastalığının tedavisinde varus osteotomisinin yeri ve etkinliği; güncel değerlendirme
}

\section{Effectiveness of varus osteotomy option in the treatment of LCP disease; current considerations}

\author{
Salih Marangoz \\ Koç Üniversitesi Hastanesi, Ortopedi ve Travmatoloji Anabilim Dalı, İstanbul
}

\begin{abstract}
Varus osteotomisi, yüz yıldan fazla bir süredir gizemi çözülemeyen Perthes hastalığının tedavisinde kapsama felsefesini yerine getiren ve sıklıkla kullanılan cerrahi yöntemlerden birisidir. Lateral pillar sınıflamasına göre, $B$ grubu ve $B / C$ grubu en fazla yarar gören grubu oluşturur. Varus osteotomisi sonrası uzun süren veya kalıcı aksama ve kısalık görülebilmesi dezavantajıdır. Bu derlemede, bu konuda yazılmış belli başlı makaleler ve sonuçları bir araya getirilmiş ve okuyucuya Perthes hastalığında yapılacak varus osteotomisi açısından bir perspektif kazandırılması amaçlanmıştır.
\end{abstract}

Anahtar sözcükler: Perthes hastalığı; Legg-Calvé-Perthes hastalı̆̆; varus osteotomisi; femoroasetabular uyum; kapsama
Varus osteotomy is one of the options that is frequently applied using containment philosophy in the treatment of Perthes disease, mystery of which has not been solved for more than 100 years. Patients in lateral pillar group B and $B / C$ would benefit the surgery most. As a disadvantage, long-standing limping and shortening could be seen postoperatively. In this review it is aimed to bring selected articles together and give the reader a perspective on the option of varus osteotomy as an alternative in the treatment of Perthes disease.

Key words: Perthes disease; Legg-Calvé-Perthes disease; varus osteotomy; femoroacetabular congruency; containment
egg-Calvé-Perthes hastalığı ya da sık kullanan şekliyle Perthes hastalığı, 100 yılı aşkın bir süredir gizemini koruyan, çocukluk çağının sık görülen kalça rahatsızlıklarından birisidir. Etiyolojisi üzerine yapılan çalışmalar süregelmekte olup tedavisi ile ilgili üzerinde fikir birliğine varılamamış birçok husus vardır. Femur başını ilgilendiren bu hastalıkta, femur başında meydana gelen değişiklikler neticesinde femoroasetabular eklem uyumunun bozulmaması için önerilen tedavi yöntemleri vardır. Bunların hepsinin de temel aldığı nokta, kapsama (containment) felsefesidir. Eklem hareket genişliğinin korunması ve femur başının asetabulum tarafindan kapsanması sayesinde, yeniden şekillenme süreci ile femur başının yuvarlaklığının ya da en azından asetabulum ile uyumunun korunması amaçlanır.

Illk olarak Axer ${ }^{[1]} 1965$ yllında, femur proksimaline yapılacak bir subtrokanterik varus derotasyon osteotomisinin Perthes hastalığının tedavisinde iyi sonuç alınabilecek bir alternatif olduğunu öne sürmüștür. Yıllar içerisinde, üzerinde en çok çalışılan, endikasyonları ve sınırlılıkları tanımlanmış bir yöntem haline gelmiştir. 1980 yılında Axer ve arkadaşları, femoral osteotominin sonuçlarını incelemiştir. ${ }^{[2]}$ Esas olarak, femur başının dışa taşan kısmının asetabulum tarafından daha fazla zarar görmesinin engellenmeye çalışılması vurgulanmış ve kimlerin en çok yarar görebileceğine dair çıkarımlar yapılmıştır. Sonuçlar genel olarak yüzde 83 oranında tatmin edici iken, hastaların yüzde 17'sinde teknik başarısız olmuştur. 2004 yılında yayımlanan, uzun dönem sonuçları yansıtan çok merkezli ileriye dönük bir çalışmada ${ }^{[3]}$ femoral varus osteotomisi veya Salter iliak (innominate) osteotomisi yapılan spesifik bir hasta grubunda, sonuçların daha iyi olduğu belirtilmiştir. Wiig ve arkadaşları ${ }^{[4]}$ tarafından Norveç'te yürütülen çok merkezli bir çalışmada, altı yaşından büyük \%50'den fazla femur başı nekrozu olan hastada, fizik tedavi, abduksiyon ortezi ve proksimal femoral varus osteotomisi karşılaştırılmıştır. Varılan sonuç, femoral osteotominin anlamlı olarak daha iyi sonuç verdiğidir. Altı yaşının altında yapılan tedaviler arasında bir fark bulunamamıştır. Dolayısıyla, bu yazarlar abduksiyon

- İletişim adresi: Doç. Dr. Salih Marangoz, Koç Üniversitesi Hastanesi, Ortopedi ve Travmatoloji Anabilim Dalı, İstanbul e-posta: salih@marangoz.org

- Geliș tarihi: 20 Șubat 2017 Kabul tarihi: 20 Șubat 2017 
ortezi kullanımının terk edilmesi gerektiğini savunmuşlardır. ${ }^{[4]}$ Terjesen ve arkadaşları, Catterall Evre 4 olan hastalarda da varus osteotomisinin başarılı sonuçlar verdiğini göstermişlerdir. ${ }^{[5]}$ Saran ve arkadaşları, yayımladıkları meta-analizde, altı yaş ve üzeri çocuklarda yapılan femoral varus osteotomisi veya Salter iliak osteotominin fragmantasyon evresi sırasında veya öncesinde uygulanması halinde, femoral baş yuvarlaklığını arttırdığı sonucuna varmışlardır (Şekil 1). ${ }^{6]}$

Varus osteotomisini yapabilmenin öncelikli koşulu, hastanın ekleminin hareket genişliğinin, özellikle de abduksiyonunun tam olması, kısıtlılık olmamasıdır. ${ }^{[7]}$ Biyolojik ve biyomekanik olarak yarar sağlanabilmesi için cerrahinin, hastalığın klinik ve radyolojik olarak erken evrelerinde yapılması istenir. ileri evrelerde de, ağrılı ve deforme kalçalarda, ancak kurtarma amacıyla yapılabilir. Femoral osteotominin zamanlaması tartışılan konulardan biridir. Bazı yazarlar, hastalığın bulgularının ortaya çıkmasından sonraki sekiz ay içerisinde ameliyatın yapılmasını tavsiye ederler. ${ }^{[8]} 2003$ yılında Joseph ve arkadaşları tarafından femoral osteotomi yapılmış 97 çocuğun sonuçları incelenmiş ve kapsama cerrahisinin, hastalığın başlangıç safhasında ya da ileri fragmantasyon evresine gelmeden önce yapılması gerektiği sonucuna varılmıştır. ${ }^{[9]}$ Ameliyatın zamanlamasının, yapılacak değerlendirmeyi etkileyebilecek bir parametre olduğu vurgulanmıştır. ${ }^{[9,10]}$ Diğer yazarlar da, kapsama cerrahisinin fragmantasyon evresinin ileri safhasından önce yapılmasına vurgu yapmıştır. ${ }^{[3]} 2004$ yılında Herring ve arkadaşları tarafından yapılan 438 hastanın 451 kalçasının incelendiği çok merkezli ileriye dönük çalışmada, beş farklı tedavi yönteminin sonuçları değerlendirilmiştir. Bunlar, sırasıyla; tedavi yapılmaması, breys tedavisi, hareket genişliği egzersizleri, femoral osteotomi ve iliak osteotomidir. Bütün hastalar, hastalık ortaya çıktığında 6-12 yaşları arasında olup daha önce bir tedavi almamışlardır. İskelet matüritesine erişen 337 hastanın 345 kalçası çalışmaya dahil edilmiştir. Bütün kalçalar, modifiye lateral pillar sınıflamasına ve Stulberg sınıflamasına göre değerlendirilmiştir. Lateral pillar Grup A hastalarında prognoz çok iyi olduğu için, bu hastalara özgün bir tedavi uygulanmasına gerek duyulmadığı vurgulanmıştır.

Hastalığın ortaya çıkışı sekiz yaş üstünde olan, lateral pillar B ve B/C grup hastalarda, cerrahi tedavinin sonuçlarının cerrahi yapılmayanlara göre anlamlı olarak daha iyi olduğu görülmüş̧tür. Hastalığın ortaya çıkışı kronolojik olarak sekiz yaş ve altı olan ya da kemik yaşı $\leq 6$ olan lateral pillar B grubu hastalarda, cerrahi tedavi yapılmayan ve yapılan gruplar arasında fark görülmemiştir.

Her hâlükârda, semptomatik tedavi ile sonuçlar iyidir. B/C grupta prognoz biraz daha kötü olsa da, cerrahi tedaviden çok yarar görmemiştir. Lateral pillar $C$ grubu hastalarda en az tatmin edici sonuçlar elde edilmiş olup, cerrahi yapılmış olması ile olmaması arasında bir fark saptanmamıştır. ${ }^{[3]}$ Friedlander ve arkadaşları, 2000 yılında, proksimal femoral varus osteotomisi yaptıkları 116 lateral pillar grup $B$ ve $C$ Perthes hastasını incelemişler ve yaştan bağımsız olarak, proksimal varus osteotomisinin güvenle uygulanabileceği ve başarılı sonuçlar elde edilebileceğini rapor etmişlerdir. ${ }^{[11]}$ Ancak, 2005 yılında Aksoy ve arkadaşları, lateral pillar grup $C$ hastalarında yaptıkları femoral varus osteotomisi deneyimlerini yayımlamışlardır. Yirmi dört hastanın 26 kalçasını inceledikleri çalışmada, hastaların ortalama yaşı 8,3 olup 11 hasta dokuz yaşından büyüktür. Ortalama 13 yıllık takip neticesinde varılan sonuç, özellikle dokuz yaşından sonra daha belirgin olmak üzere, lateral pillar $C$ grup hastalarda uygulanan femoral varus osteotomisinin kötü prognoza sahip olduğudur (Şekil 2). ${ }^{[12]}$ Noonan ve arkadaşları da, dokuz yaşından büyük 17 hastanın 18 kalçasına yapılan varus osteotomisinin sonuçlarının incelendiği çalışmalarında, varus osteotomisi sayesinde 10 yaşından daha küçük hastalarda 10 yaşından daha büyük hastalara kıyasla daha iyi sonuçlar elde edildiğini göstermişlerdir. ${ }^{[13]} 2005$ yılında Joseph ve arkadaşları, femoral osteotominin Perthes hastalığının seyrine olan etkisini incelemiş, femoral osteotomi yapılan 314 hastayı ameliyat edilmeyenlerle kıyaslamışlardır. Verilerin ışığında, femoral osteotominin doğal seyri açık bir şekilde etkilediği sonucuna varılmıştır. Avasküler nekroz evresinde ameliyat edilenlerin \%34'ü fragmentasyona uğramamış, hastalığın süresi kısalmıştır. Fragmante olanların ise fragmantasyon evresinde kalma süreleri daha kısa olmuştur. Femur başının taşma boyutu, deformasyona yatkınlığın en fazla olduğu bu evrede en aza indirgenmiştir. Metafizyel genişleme ve takibinde ortaya çıkan baş genişlemesi de, femoral osteotomi yapılan hastalarda daha az olmuştur. Femoral osteotomi yapılan hastalarda, femur başının yuvarlaklı̆̆ını koruma oranı artmıştır. Varus osteotomisinin bu yararlı etkileri en fazla, ameliyat avasküler nekroz safhasında veya erken fragmantasyon evresinde yapıldığında görülmüştür. ${ }^{[10]} 2008$ yılında Castaneda ve arkadaşları ${ }^{[14]}$ varus osteotomisi yaptıkları 73 ve cerrahi yapılmayan 48 olmak üzere toplam 121 hastalarını geriye dönük olarak incelemişlerdir. Bu hastaların 70'i lateral pillar $B$ ve 51 'i lateral pillar $C$ grubu hastalardır. Vardıkları sonuçlar, Herring ve arkadaşları[ ${ }^{[3]}$ sonuçlarından farklıdır. Lateral pillar B veya $C$ grubu hastalarda hastalığın ortaya çıkışı sekiz yaşından küçük de olsa büyük de olsa, sonuçlar açısından bir farklılık görülmediğini belirtmişler, ameliyatın doğal seyirden daha iyi bir etkisi olmadığı sonucuna varmışlardır. Üstelik, varus osteotomisi yapılan hastalarda, cerrahi yapılmayanlara 

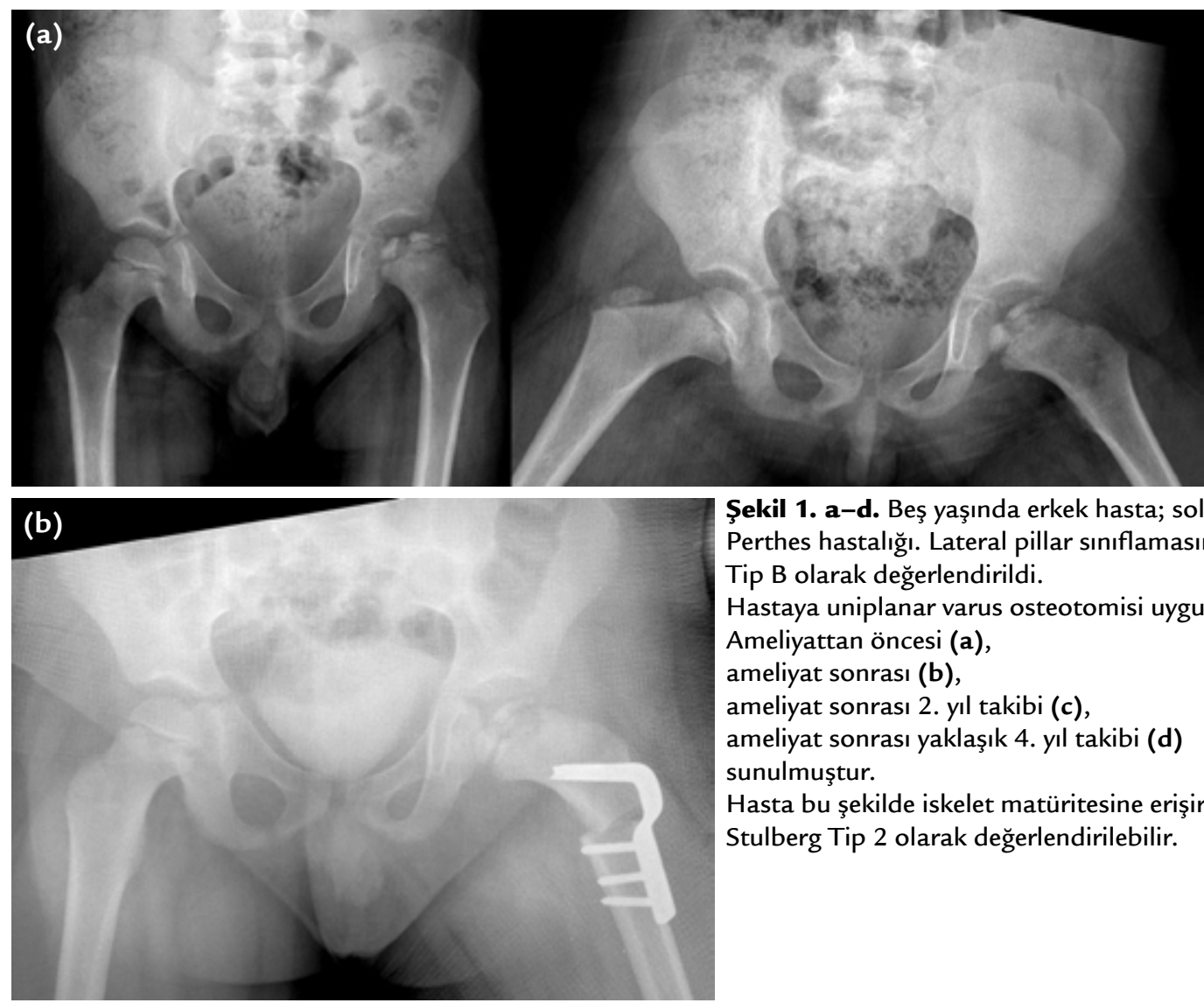

Şekil 1. a-d. Beş yaşında erkek hasta; sol kalça Perthes hastalığı. Lateral pillar sınıflamasına göre Tip B olarak değerlendirildi.

Hastaya uniplanar varus osteotomisi uygulandı. Ameliyattan öncesi (a),

ameliyat sonrası (b),

ameliyat sonrası 2. yıl takibi (c),

ameliyat sonrası yaklaşık 4. yıl takibi (d) sunulmuştur.

Hasta bu şekilde iskelet matüritesine erişirse, Stulberg Tip 2 olarak değerlendirilebilir.
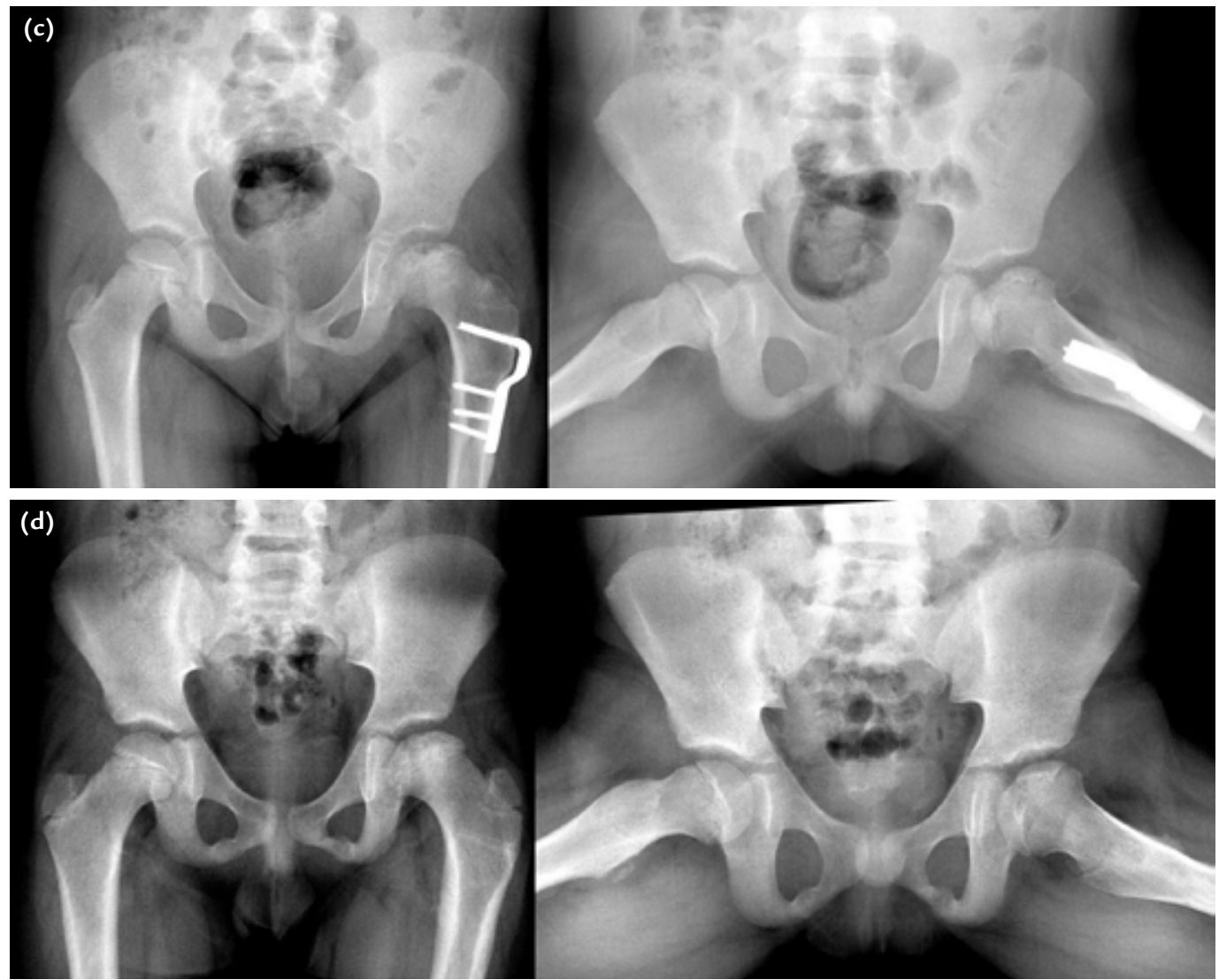

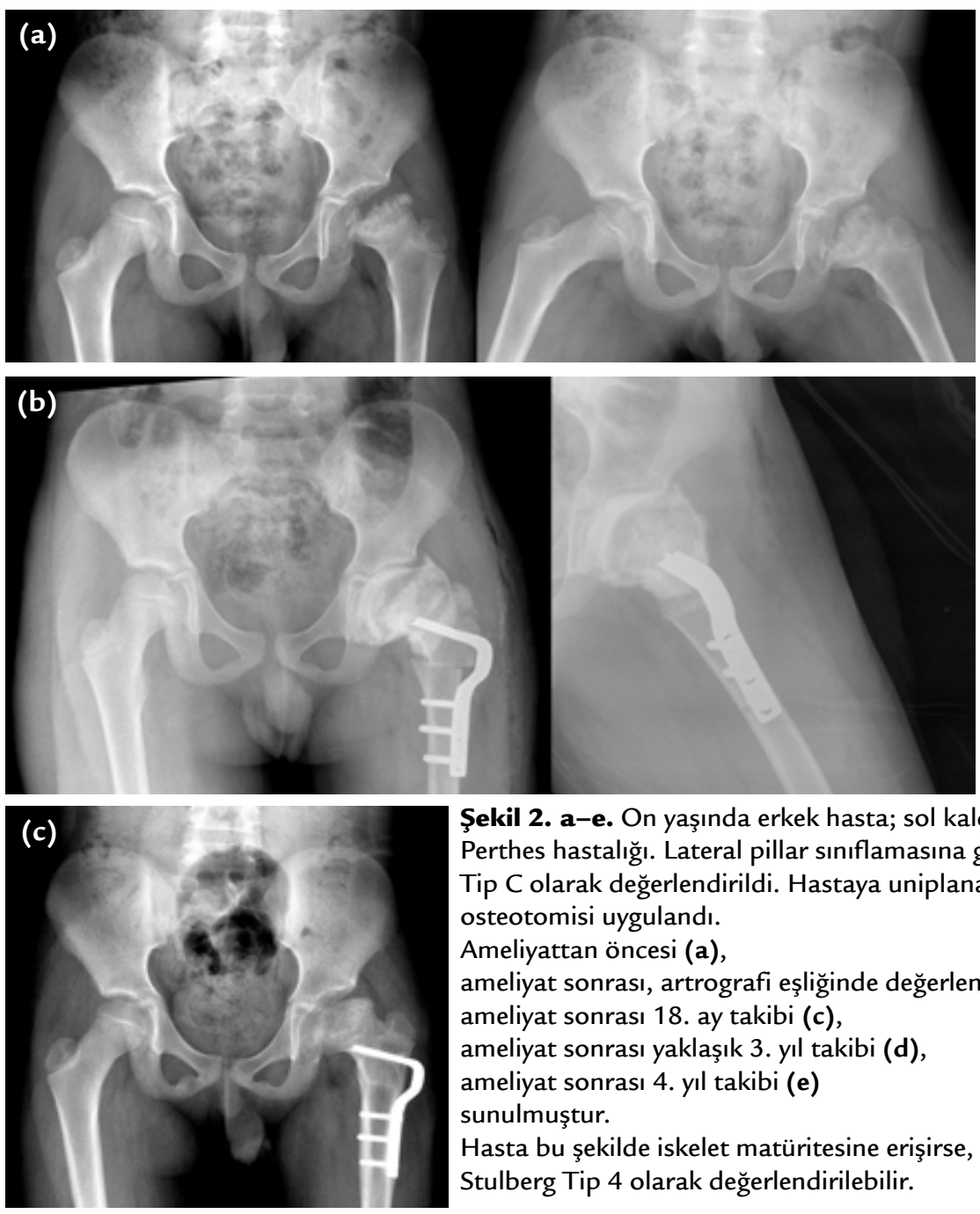

Şekil 2. a-e. On yaşında erkek hasta; sol kalça Perthes hastalığı. Lateral pillar sınıflamasına göre Tip C olarak değerlendirildi. Hastaya uniplanar varus osteotomisi uygulandı.

Ameliyattan öncesi (a),

ameliyat sonrası, artrografi eşliğinde değerlendirme (b), ameliyat sonrası 18 . ay takibi (c),

ameliyat sonrası yaklaşık 3. yıl takibi (d),

ameliyat sonrası 4. yıl takibi (e)

sunulmuştur.

Hasta bu şekilde iskelet matüritesine erişirse, Stulberg Tip 4 olarak değerlendirilebilir.
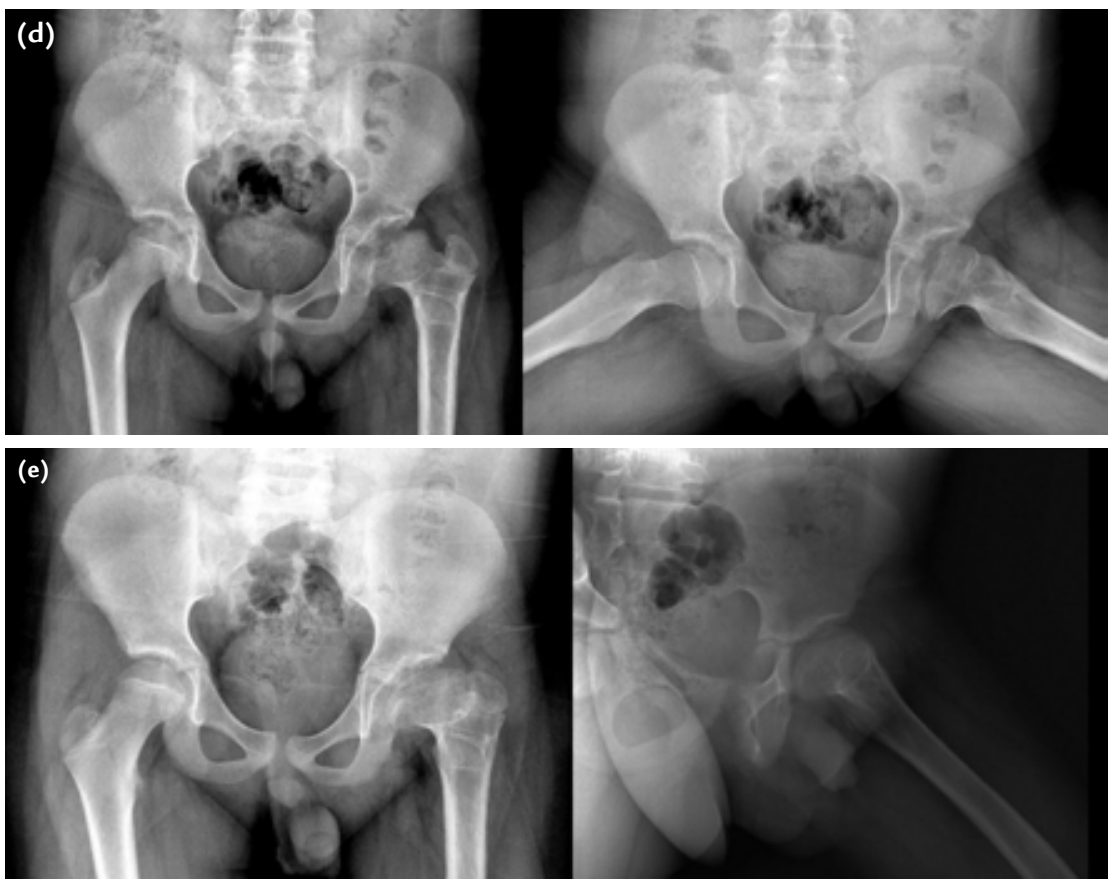
kıyasla, ilave olarak sebat eden aksama kaldığı gözlenmiştir. Bunun da kısmen, varus nedeniyle ortaya çıkan kısalığa bağlı olabileceği öne sürülmüştür.

Femoral varus osteotomisinin iyileşmeye olan etkisinin incelenmesi amacıyla yapılan bazı çalışmalarda, kemikte herhangi bir açılanma olmadan yapılan "biyolojik" osteotomilerin, iyileşmeye olan etkisi açısından bir fark yaratmadığı gözlenmiştir. ${ }^{[15,16]}$ Varustaki femur boynunun yeniden şekillenmesi, tamamen femur başının büyüme potansiyeline bağımlıdır ve bunun önceden tahmin edilmesi zordur. Bazı hastalarda abduktor topallama, yani abduktor kas güçsüzlüğü gelişebilir ve trokanterik aşırı büyüme olasılığı olan hastalarda trokanterik apofizyodez uygulanması tavsiye edilir. ${ }^{[17]}$ Cerrahi tekniğin ayrıntıları arasında da, üzerinde henüz tam fikir birliğine varılamamış hususlar vardır. İlk başlarda bazı yazarlar, ne kadar çok varus yapılırsa o kadar iyi olacağı görüşünü savunurlardı; ancak yapılan çalışmalarda, varus miktarının fazla olmasının aksamanın kalıcı olmasına yol açabileceği, üstelik Stulberg sınıflaması açısından daha fazla varus yapılmasının daha iyi sonuç vermediği gösterilmiştir. ${ }^{[18]}$ Cerrahi teknik açısından, anestezi altında artrografi ile dinamik bir muayene yapıp kalça ekleminin en uyumlu olduğu pozisyonlar belirlenebilir. ${ }^{[18]}$ Herring ve arkadaşları, yürüttükleri ileriye dönük çalışma neticesinde, elde edilmesi gereken femur baş-boyun açısını $110-115^{\circ}$ olarak tavsiye etmiş̧lerdir. ${ }^{[3]}$ Ancak, ideal olarak yapılacak varus miktarı $10-15^{\circ}$ 'yi geçmemelidir. ${ }^{[18]}$

Eğer varus osteotomisi hastalığın ileri evrelerinde yapılacak ise, deforme hale gelmiş femur başını asetabulum içerisinde kapsayabilmek için daha fazla varus derecesi verilmesi gerekebilir. ${ }^{[19]}$ Femoral varus osteotomisi sonrası yeniden şekillenme, yapılan bir çalışmaya göre, yaştan bağımsız olarak gerçekleşmektedir. Herceg ve arkadaşlarına göre, en fazla yeniden şekillenme ilk 3-4 yıl içerisinde olmaktadır. Femur boyuncisim açısını da içerecek şekilde yeniden şekillenme, hastanın sekiz yaşından küçük veya büyük olmasına göre anlamlı bir fark göstermemiştir. ${ }^{[20]}$ Kırk hastanın 43 kalçasına uygulanan femoral varus osteotomisinin 33 yıllık takibinin sonuçlarını inceleyen bir çalışma$\mathrm{da}^{[21]}$, proksimal femoral varus osteotomisinin uzun dönem sonuçlarının iyi olduğu ve Stulberg sınıflamasının hastanın fonksiyonel sonuçlarını yansıtmada iyi bir ölçüt olduğu belirtilmiştir. Yine, ortalama 42 yıllık sonuçları inceleyen başka bir çalışmada ${ }^{[22]}$ da femoral varus osteotomisi yapılan hastaların çoğunluğunda klinik ve radyografik sonuçların iyi olduğu vurgulanmıştır. Tercier ve arkadaşları, 2012 yılında femoral varus osteotomisi yaptıkları 101 hastada, varus osteotomisi sonrası alt ekstremitede valgus dizilimi gelişip gelişmediği hipotezini incelemişler, varus osteotomisi yapılmış olması ile valgus dizilimi arasında anlamlı bir fark bulamamışlardır. [23] Femoral varus osteotomisinin yararlı olup olmayacağını her zaman öngörmek mümkün olmayabilir. Kamegaya ve arkadaşları bu açıdan, artrografi eşliğinde yapılan bazı ölçümlerin cerraha ek bilgi sağlayabileceğini iddia etmişlerdir. Epifizyel slip-in endeksi, bu açıdan kullanılabilecek bir parametre olarak öne sürülmüştür. ${ }^{[24]}$

Femoral varus osteotomisinin sonucunda bazı komplikasyonlar görülebilir. Bunlar arasında; aşırı miktarda varus verilmiş olması en önde gelmekle birlikte, varusun yeniden şekillenmesinin yeteri kadar olmaması, rotasyonel osteotomi sonrası hastada eksternal rotasyon deformitesinin sebat etmesi, ekstremitenin kısalması, abduktor topallaması, trokanterik aşııı büyüme, tespit materyalinin (plak) çıkarılma gerekliliği, plağı çıkardıktan sonra kırık oluşması, gecikmiş kaynama ya da kaynamama olması ihtimalleri sayılabilir. iliak osteotomi ile kıyaslandığında, femoral osteotomi, ekstremitede daha fazla kısalığa ve daha fazla abduktor topallamasına yol açar. Bu gibi bazı nedenlerden ötürü de, bazı yazarlar femoral osteotomiyi ileri yaşlarda yapmayı tercih etmezler. ${ }^{[19]}$

Sonuç olarak, varus osteotomisi Perthes hastalığında kapsamayı sağlamaya yönelik tercih edilen cerrahi yöntemlerden birisidir. Üzerinde yapılmış epey miktarda çalışma ve uzun dönem takip araştırması mevcuttur. Hastalığın fragmantasyon evresinin başlangıç aşamasında, özellikle lateral pillar $B$ veya $B / C$ olan hasta gruplarında, en fazla yarar beklenilerek yapılması tavsiye edilir. Hastalığın ortaya çıkış yaşının 6-9 arasında olması, hastanın ameliyattan yarar görebileceğine işaret edebilir. Varus osteotomisi sonrası dezavantaj olarak, aksama kalabileceğini akıldan çıkarmamak ve bunu önceden hastanın ailesine anlatmak gereklidir.

\section{KAYNAKLAR}

1. Axer A. Subtrochanteric osteotomy in the treatment of Perthes' disease: A preliminary report. J Bone Joint Surg Br 1965;47:489-99.

2. Axer A, Gershuni DH, Hendel D, Mirovski Y. Indications for femoral osteotomy in Legg-Calvé-Perthes disease. Clin Orthop Relat Res 1980;(150):78-87.

3. Herring JA, Kim HT, Browne R. Legg-Calve-Perthes disease. Part II. Prospective multicenter study of the effect of treatment on outcome. J Bone Joint Surg Am 2004;86-A(10):2121-34.

4. Wiig O, Terjesen T, Svenningsen S. Prognostic factors and outcome of treatment in Perthes' disease: a prospective study of 368 patients with five-year follow-up. J Bone Joint Surg Br 2008;90(10):1364-71. Crossref

5. Terjesen T, Wiig O, Svenningsen S. Varus femoral osteotomy improves sphericity of the femoral head in older children with severe form of Legg-Calvé-Perthes disease. Clin Orthop Relat Res 2012;470(9):2394-401. Crossref 
6. Saran N, Varghese R, Mulpuri K. Do femoral or salter innominate osteotomies improve femoral head sphericity in Legg-Calve-Perthes disease? A meta-analysis. Clin Orthop Relat Res 2012;470(9):2383-93. Crossref

7. Weinstein SL. Legg-Calvé-Perthes Syndrome. In: Weinstein SL, Flynn JM, editor. Lovell and Winter's Pediatric Orthopaedics. Philadelphia: Wolters Kluwer; 2014. p.1112-64.

8. Lloyd-Roberts GC, Catterall A, Salamon PB. A controlled study of the indications for and the results of femoral osteotomy in Perthes' disease. J Bone Joint Surg Br 1976;58(1):31-6.

9. Joseph B, Nair NS, Narasimha Rao K, Mulpuri K, Varghese G. Optimal timing for containment surgery for Perthes disease. J Pediatr Orthop 2003;23(5):601-6.

10. Joseph B, Rao N, Mulpuri K, Varghese G, Nair S. How does a femoral varus osteotomy alter the natural evolution of Perthes' disease? J Pediatr Orthop B 2005;14(1):10-5.

11. Friedlander JK, Weiner DS. Radiographic results of proximal femoral varus osteotomy in Legg-Calvé-Perthes disease. J Pediatr Orthop 2000;20(5):566-71.

12. Aksoy MC, Cankus MC, Alanay A, Yazici M, Caglar O, Alpaslan AM. Radiological outcome of proximal femoral varus osteotomy for the treatment of lateral pillar group-C Legg-Calvé-Perthes disease. J Pediatr Orthop B 2005;14(2):88-91.

13. Noonan KJ, Price CT, Kupiszewski SJ, Pyevich M. Results of femoral varus osteotomy in children older than 9 years of age with Perthes disease. J Pediatr Orthop 2001;21(2):198-204.

14. Castañeda P, Haynes R, Mijares J, Quevedo H, Cassis N. Varus-producing osteotomy for patients with lateral pillar type B and C Legg-Calvé-Perthes disease followed to skeletal maturity. J Child Orthop 2008;2(5):373-9. Crossref

15. Clancy $M$, Steel $\mathrm{HH}$. The effect of an incomplete interochanteric osteotomy on Legg-Calvé-Perthes disease. J Bone Joint Surg Am 1985;67(2):213-6.
16. Kendig RJ, Evans GA. Biologic osteotomy in Perthes disease. J Pediatr Orthop 1986;6(3):278-84.

17. Karpinski MR, Newton G, Henry AP. The results and morbidity of varus osteotomy for Perthes' disease. Clin Orthop Relat Res 1986;(209):30-40.

18. Kim HK, da Cunha AM, Browne R, Kim HT, Herring JA. How much varus is optimal with proximal femoral osteotomy to preserve the femoral head in Legg-Calvé-Perthes disease? J Bone Joint Surg Am 2011;93(4):341-7. Crossref

19. Kim HK, Herring JA. Legg-Calvé-Perthes Disease. In: Herring JA, editor. Tachdjian's Pediatric Orthopaedics. Saunders; 2014. p.580-629.

20. Herceg MB, Cutright MT, Weiner DS. Remodeling of the proximal femur after upper femoral varus osteotomy for the treatment of Legg-Calvé-Perthes disease. J Pediatr Orthop 2004;24(6):654-7.

21. Beer $Y$, Smorgick $Y$, Oron A, Mirovsky Y, Weigl D, Agar G, Shitrit R, Copeliovitch L. Long-term results of proximal femoral osteotomy in Legg-Calvé-Perthes disease. J Pediatr Orthop 2008;28(8):819-24. Crossref

22. Shohat N, Copeliovitch L, Smorgick Y, Atzmon R, Mirovsky Y, Shabshin N, Beer Y, Agar G. The Long-Term Outcome After Varus Derotational Osteotomy for Legg-Calvé-Perthes Disease: A Mean Follow-up of 42 Years. J Bone Joint Surg Am 2016;98(15):1277-85. Crossref

23. Tercier S, Shah H, Siddesh ND, Joseph B. Does proximal femoral varus osteotomy in Legg-Calvé-Perthes disease predispose to angular mal-alignment of the knee? A clinical and radiographic study at skeletal maturity. J Child Orthop 2013;7(3):205-11. Crossref

24. Kamegaya M, Saisu T, Takazawa M, Nakamura J. Arthrographic indicators for decision making about femoral varus osteotomy in Legg-Calvé-Perthes disease. J Child Orthop 2008;2(4):261-7. Crossref 